\title{
Discrete analysis of open stope stability
}

\author{
B Sainsbury Monash University, Australia \\ D Sainsbury Mining One Pty Ltd, Australia
}

A Vakili Mining One Pty Ltd, Australia

\begin{abstract}
The established (industry standard) practice to design stable stope spans in jointed rock is to use empirical methods. Experience at a number of open stoping operations has shown that empirical methods can produce unreliable and ambiguous results when applied to particular geological settings. A numerical modelling methodology has been developed and validated for a case study of hanging wall overbreak at a narrow vein open stoping operation. In this case, the methodology has proven successful in simulating the historical stope performance through the analysis of the actual stope geometry, stope wall orientations, extraction sequence, in situ stresses, discrete joint fabric and rock mechanical properties.
\end{abstract}

\section{Introduction}

Successful open stope mining requires a delicate balance between optimising ore recovery and minimising ore dilution. Lost ore recovery and unplanned dilution can result in a significant economic impact to stoping operations. Previous work on narrow vein orebodies completed by Stewart and Trueman (2008) shows the increasing economic effect of unplanned dilution on decreasing ore width - Figure 1(a). A study of 115 mine sites from around the world (Berry \& McCarthy 2006) has shown that the majority of mining risks have links back to geoscience inputs, as shown in Figure 1(b).
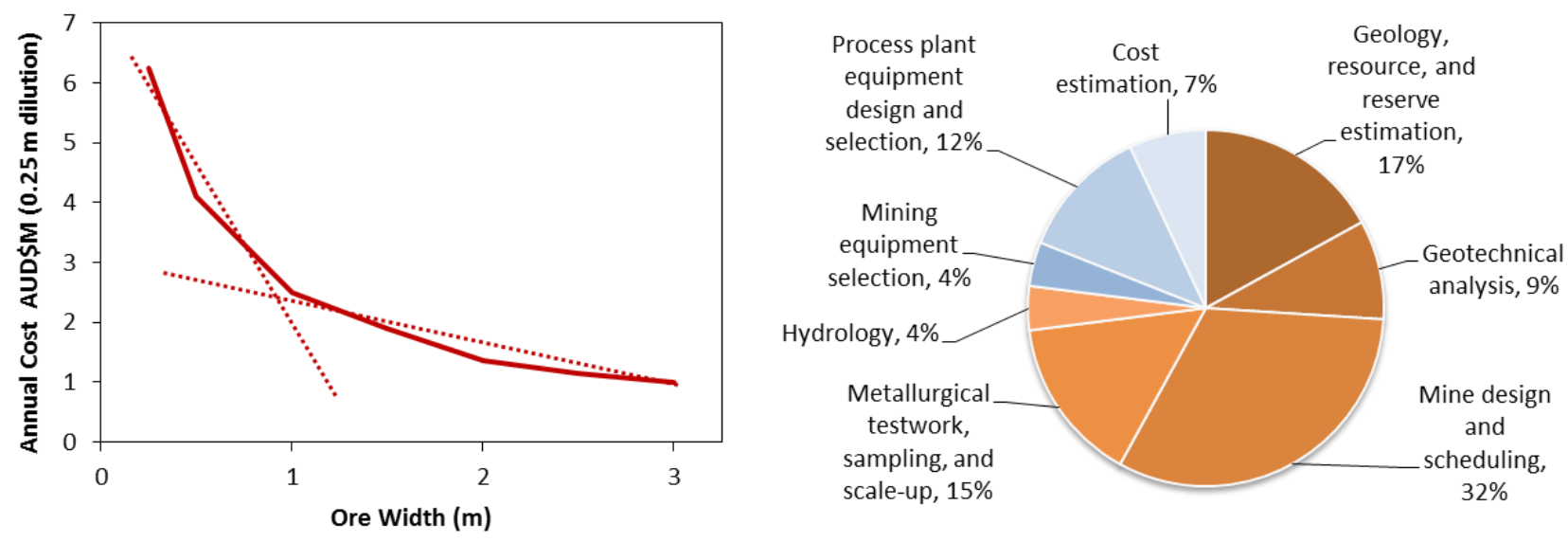

Figure 1 (a) annual operating cost for $0.25 \mathrm{~m}$ of dilution for typical narrow vein mine (modified after Stewart \& Trueman 2008); (b) sources of reconciliation error in mining (modified after Berry \& McCarthy 2006)

When stope performance is reconciled within Berry and McCarthy's (2006) dataset, 41\% of poor performance results can be attributed to design issues. The timeframe afforded to completing detailed engineering design is sometimes insufficient since, in many cases, mining commences with resource drilling marginally ahead of mining. In these cases, efficiency and design reliability is critical in minimising economic risk. In order for a mine to maximise economic benefit, robust and efficient techniques are needed to predict the influence of ground conditions and mining practice on stope performance. 


\section{Stope design - empirical approaches}

The established practice for the design of stable stope spans in jointed rock is to use empirical methods that may include Mathews et al. (1981), Potvin (1988), Mawdesley et al. (2001), Capes (2009) and Suorineni (2010). In each of these methods, stope stability and dilution (though an estimate of equivalent linear overbreak slough (ELOS)) can be determined based on the ratio of a stability number to the hydraulic radius (HR) of the stope face under consideration. In the instance of Mathews et al. (1981), the stability number is determined from a range of in situ rock mass characteristics and conditions that include; rock quality designation (RQD), joint number $\left(J_{n}\right)$, joint roughness $\left(J_{r}\right)$, joint alteration $\left(J_{a}\right)$, stress, joint orientation and expected failure mode. A discussion regarding some of these input parameters and their influence on predicted stope performance is provided below.

\subsection{Consideration of empirical input data}

\subsubsection{Rock quality designation}

The characterisation of the highly complex arrangement of joining in a rock mass by this parameter can be misleading; for example, a RQD of $100 \%$ can be achieved in a rock mass that has a discontinuity spacing of just $0.11 \mathrm{~m}$, but a joint spacing of $0.02 \mathrm{~m}$ smaller (at $0.09 \mathrm{~m}$ ) will provide a RQD of $0 \%$. Using empirical design techniques, these rock masses would be classified as having very different mechanical responses. However, experience and common sense would suggest they would respond in a similar manner at the stope scale. The misleading nature of this input parameter for empirical design purposes is highlighted in the extreme example below.

Given a stoping scenario where $\sigma_{\max }$ equals $26 \mathrm{MPa}$ and the hanging wall span and orientation are $20 \mathrm{~m}$ and $45^{\circ} / 290^{\circ}$ respectively, the stable unsupported span can be calculated for a consistent joint set orientation of $80^{\circ} / 290^{\circ}$ with spacing of 0.09 and $0.11 \mathrm{~m}$. The stability results are presented in Table 1.

Table 1 Effect of stable span prediction based on variation in joint spacing by $0.02 \mathrm{~m}$

\begin{tabular}{ccccccccccc}
\hline Spacing & RQD & Jn & Jr & Ja & A & B & C & N' & HR & $\begin{array}{c}\text { Stable unsupported } \\
\text { Stable unsupported } \\
\text { secondary dimension }\end{array}$ \\
\hline $0.11 \mathrm{~m}$ & 100 & 6 & 2 & 4 & 0.2 & 0.8 & 6 & 5.9 & 5 & $17 \mathrm{~m}$ \\
$0.09 \mathrm{~m}$ & 0 & 6 & 2 & 4 & 0.2 & 0.3 & 6 & 0.0 & $<1$ & $<1 \mathrm{~m}$ \\
\hline
\end{tabular}

In this example, the change in the joint spacing from 0.09 to $0.11 \mathrm{~m}$ increases the expected stable unsupported stope span from less than 1 to $17 \mathrm{~m}$. Although extreme, this example highlights the need for experience and engineering judgement to be exercised with empirical techniques. It is also clear that unless sensitivities in the input rock mass parameters are considered, then empirical approaches may result in misleading design parameters.

\subsubsection{Stress}

The potential stress paths that a rock mass experiences around an underground excavation are illustrated in Figure 2 (after Martin et al. 1999). The presented stress paths show that for most stoping scenarios, the rock mass in the hanging wall is unloaded (e.g. experiences a decrease in $\sigma_{3}$ ) and will be most likely to undergo tensile failure. Martin (1997) also shows that, in addition to a decrease in $\sigma_{3}$ in the hanging wall, the direction of the major principal stresses are also rotated. With respect to empirical methods, the orientation of the stopes relative to the rotating stress field is generally not considered. 


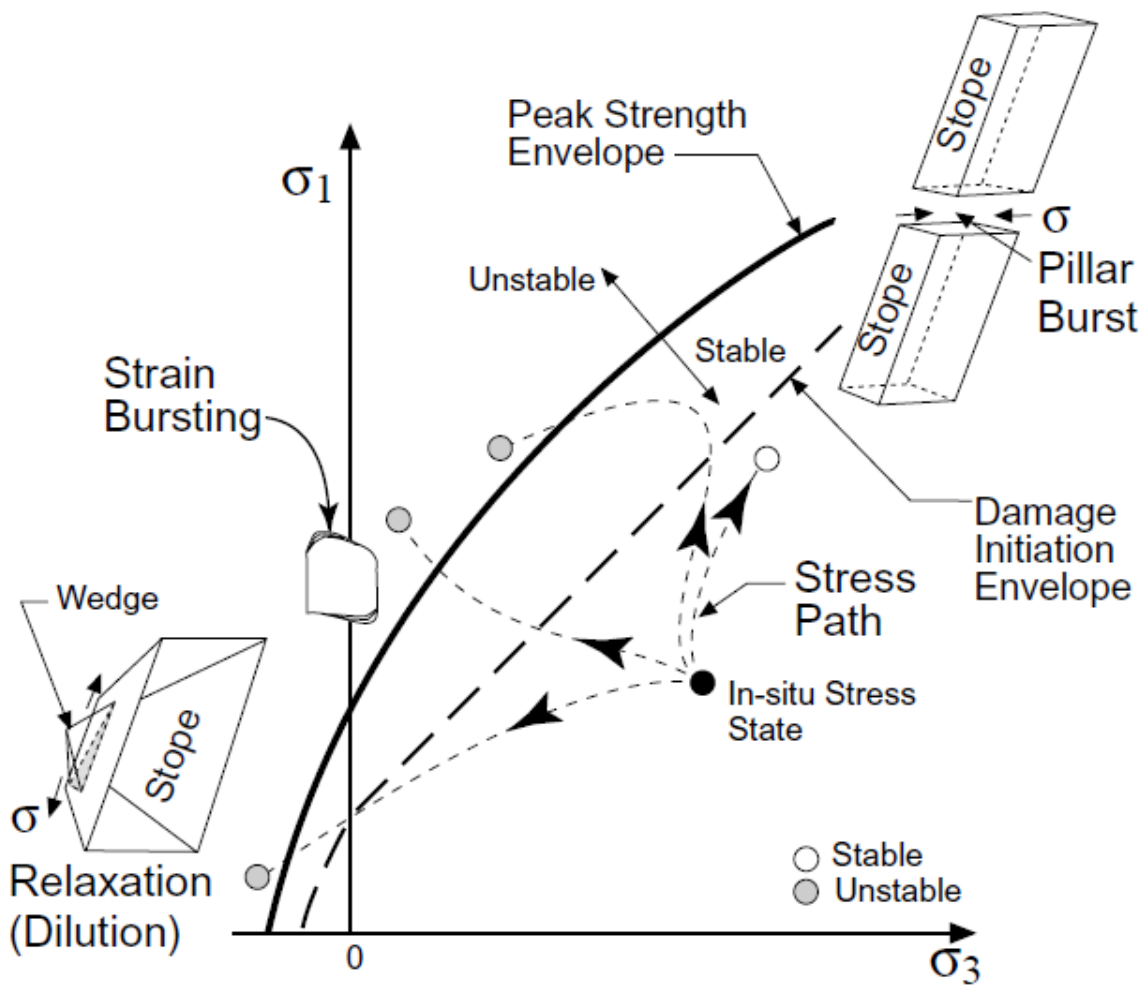

Figure 2 Illustration of possible stress paths near underground openings (after Martin et al. 1999)

In some cases, stoping induced stresses (as inputs to the empirical design approaches) are estimated based on linear-elastic numerical models. Andrieux et al. (2007) have previously shown how simplified constitutive relationships can provide significant variance in the location of induced stresses within a regional stoping sequence.

\subsubsection{Critical joint orientation}

The selection of a critical joint orientation for empirical stope assessment techniques will always be subjective. Numerical modelling conducted by Bewick and Kaiser (2009) has previously highlighted the impact of hanging wall stability based on the stope surface, fault location along this surface, joint confinement and rock block strength. Suorineni et al. (1999) have developed a fault factor for incorporation into the stability graph method; however, this still requires the designer to make decisions regarding fault hierarchy.

\subsection{Empirical stope performance case studies}

Experience at a number of open stoping operations has shown that empirical methods can produce unreliable and ambiguous results when applied to particular geological settings. A summary of some of the published case histories is provided below.

\subsubsection{Olympic Dam}

The historical performance of 460 stope surfaces at Olympic Dam has previously been considered by Oddie and Pascoe (2005) and, later, Sharp (2011). For each of the cases, the stability graph technique was used to design stable spans. Reconciliation of the stope performance was completed that considered the input stability graph information as well as other factors thought to influence stability, such as discrete major structures, poor shape and exposure time. The results of Sharp's reconciliation work are provided in Figure 3 . The majority of the 58 stopes are designed within the stable zone. However, as demonstrated by the number of failed or unstable data points, many of the predictions were erroneous. 


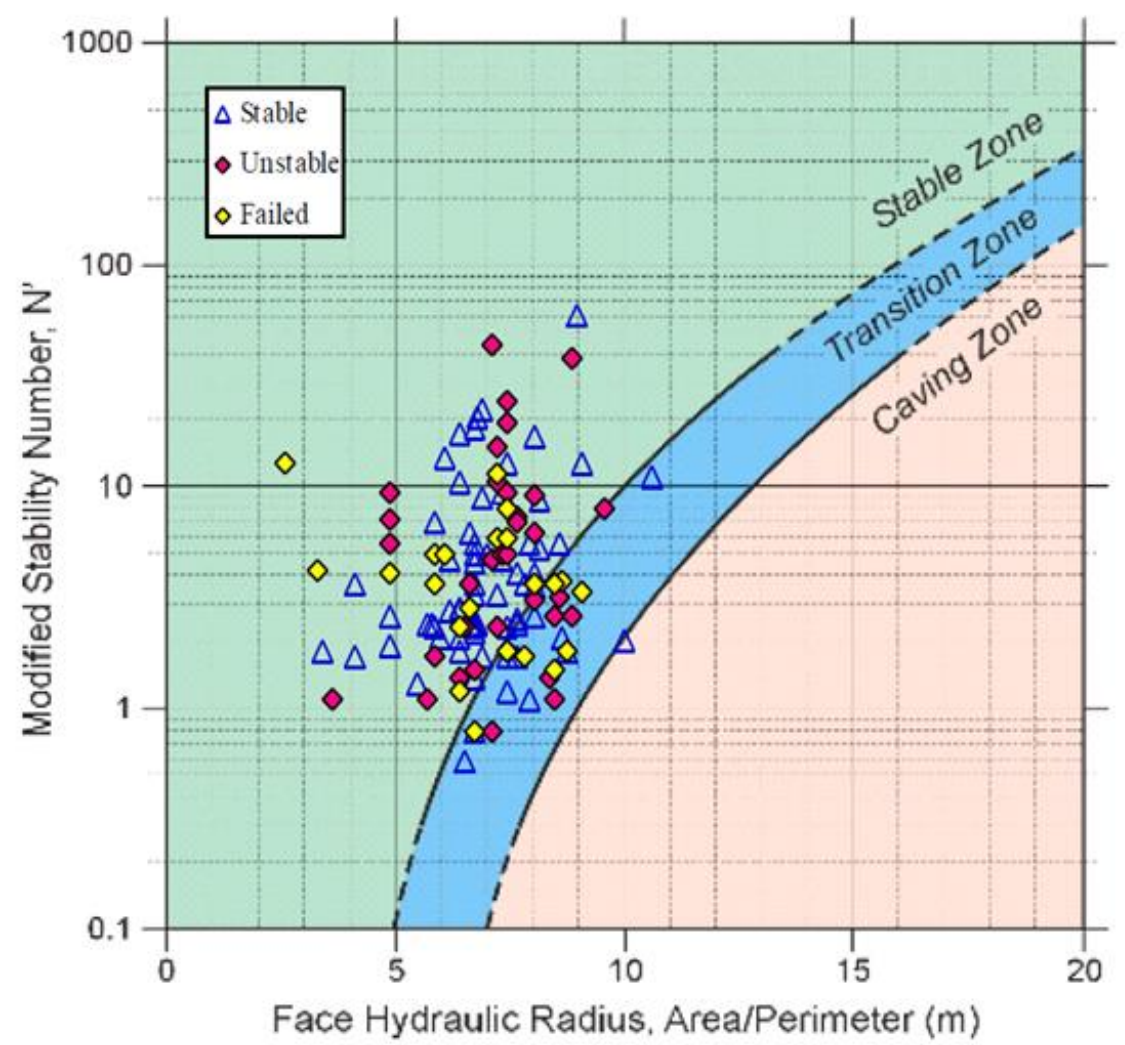

Figure 3 Crown surface actual performance plotted on the supported case history chart (after Sharp 2011)

Reconciliation of the empirically designed stopes has provided the following conclusions at Olympic Dam (after Sharp 2011). For the data analysis, an ELOS $\leq 0.75 \mathrm{~m}$ was considered 'stable'.

- Only $10 \%$ of stope walls performed in their expected design zone (stable, unsupported).

- Stope walls that were 'bent out' or 'stepped out' displayed an elevated rate of failure.

- The stability graph method did not reliably predict the performance of unsupported crowns.

- $94 \%$ of the 92 stope crowns were designed to be stable (ELOS $\leq 0.75 \mathrm{~m}$ ), only $50 \%$ remained stable.

- $40 \%$ of the stope crowns were influenced by major structures; of these, only $17 \%$ remained stable.

- Of 24 unsupported stopes, only $26 \%$ remained stable.

- The shape of the crown appeared to play a significant role in the stability performance.

\subsubsection{Favona-Waihi}

Parrott and Keall (2010) have reconciled the performance of empirically designed stopes at the Favona Mine in New Zealand. Stable spans were estimated based on the modified stability method (Potvin 1988). It was found that factors limiting the effectiveness of the stability graph method in the case of Favona included:

- The presence of discrete structures and the time dependent failure associated with susceptible weathered rock masses that were unable to be considered.

- The open stope case histories for which the stability graph technique was developed from generally presented better ground conditions than those experienced at Favona. 
In addition, Parrot and Keall (2010) make the conclusion that 'the most surprising outcome at Favona was that areas of improved ground conditions (according to Barton's Q-system) actually resulted in poorer stope performance'.

\subsection{Limitations of empirical approaches}

Empirical approaches must be used with caution; this is because predicted stope performance needs to be calibrated with observed performance for each location and variance in in situ conditions. Cepuritis and Villaescusa (2012) state that 'empirical methods do not rely on a detailed understanding of failure mechanisms and, as such, are generally only appropriate for preliminary designs'. A summary of their proposed approach to rigorous design throughout the development phases of a stoping operation is presented in Figure 4. Here, it suggested that empirical techniques can only be expected to provide a design reliability of $50 \%$ and should be limited to conceptual and pre-feasibility design stages. Feasibility studies can benefit from numerical models through their application to sensitivity studies. As mining activities progress through construction and operation, additional information becomes available and the most appropriate numerical model can be selected/validated and calibrated to the observed in situ conditions.

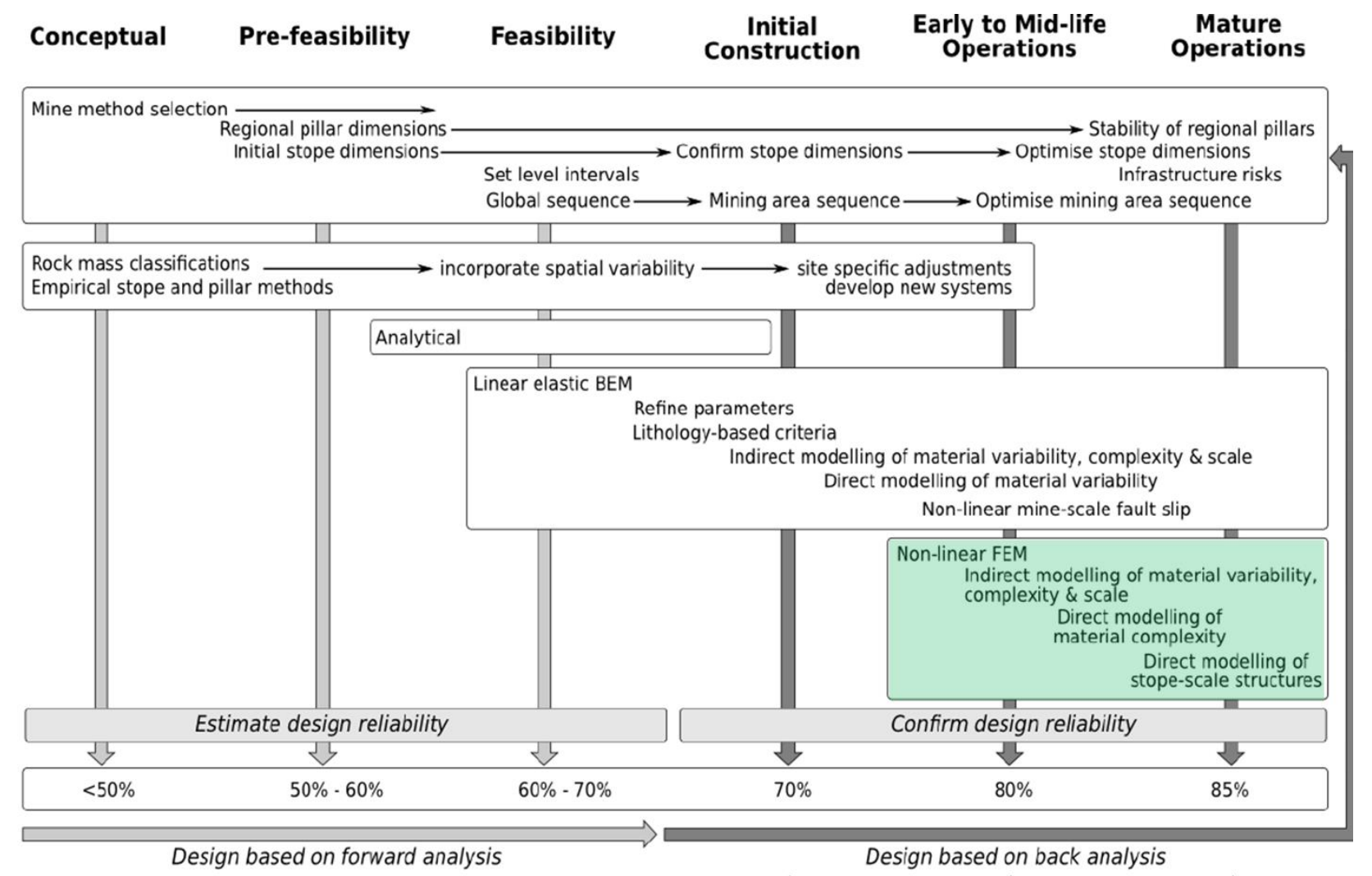

Figure 4 Evolution and interaction of key activities, together with example ranges of data, rock mass model and design reliabilities with project development (after Cepuritis \& Villaescusa 2012)

Suorineni (2010) outlines in detail the limitations of empirical stope design approaches. They can be summarised through three key fundamental failings that include the inability to:

1. Accurately reflect the highly complex nature and interaction of rock mass joint fabric and large-scale structures.

2. Consider complex, progressive rock mass failure mechanisms.

3. Consider complex stope geometries and extraction strategies. 
There have been many 'factors' that have been developed over the years to achieve a better fit to empirical stope design databases, all of which have proposed variances to the empirical design methodologies; for example, Sprott et al. (1999) added a stress damage factor. The proliferation of so many factors to amend the original empirical stability graphs has created an industry-wide problem. At the present time, no clear guidelines are available that provide recommendations on the most appropriate stability graph technique and/or accompanying factors for given ground conditions to be used for robust stope geometry design.

\section{Discrete analysis of stope design}

Today, there are many two- and three-dimensional numerical programs that allow the potential instability of any shaped underground opening to be assessed. The interpretation of the results from such analyses may be determined in terms of critical operational issues that include depth of failure, amount of dilution, stope sequencing and stable stope dimensions (Martin et al. 1999).

A full three-dimensional, mechanical solution is able to provide robust predictions that are able to account for irregular stope dimensions, complex extraction sequences, evolving in situ stresses, pre-mining and evolving discrete fracture networks (DFNs), as well as pre- and post-strength rock mass responses at various scales. Furthermore, given enough information, these simulations can provide a basis for the minimisation of the overall cost and maximisation of the reliability and utility of stope stabilisation measures.

\subsection{Hanging wall stability - Ballarat Gold Project case study application}

The Ballarat Gold Project is located in the city of Ballarat, approximately $100 \mathrm{~km}$ west of Melbourne, Victoria, Australia. Typical ore zones consist of a stockwork of quartz veining or massive quartz lobes hosted within inter-bedded sandstone, siltstone and shale sediments. The quartz can be highly fractured, particularly surrounding major geological structures, and can resemble sugar cubes in intensely fractured zones. Initial stopes on the Llanberris $648 \mathrm{~m}$ reduced level were designed using a modified Avoca (or continuous fill) stoping method. Empirical estimates based on Mathews stability chart (Mathews et al. 1981) determined a stable $21 \mathrm{~m}$ panel length for the initial void, with subsequent firings of approximately $6 \mathrm{~m}$. The inputs for the empirical hanging wall and crown stability assessment are provided in Table 2 (after Sainsbury et al. 2014).

Table 2 Empirical inputs to Mathews stability chart: Ballarat Gold Project

\begin{tabular}{|c|c|c|c|c|c|c|c|c|c|c|c|}
\hline & RQD & Jn & $\mathrm{Jr}$ & $\mathrm{Ja}$ & A & B & C & $\mathbf{N}^{\prime}$ & $\begin{array}{c}\text { Fixed } \\
\text { dimension }\end{array}$ & $\begin{array}{c}\text { Stable } \\
\text { supported } \\
\text { HR }\end{array}$ & $\begin{array}{c}\text { Stable } \\
\text { secondary } \\
\text { dimension }\end{array}$ \\
\hline Hanging wall & 30 & 6 & 2 & 4 & 0.5 & 0.2 & 2.5 & 0.53 & $23 \mathrm{~m}$ & 6 & $27 \mathrm{~m}$ \\
\hline Crown & 30 & 6 & 2 & 4 & 0.4 & 0.3 & 2.5 & 0.84 & $5 \mathrm{~m}$ & 7 & $85 \mathrm{~m}$ \\
\hline
\end{tabular}

During development of the initial void, when the open span was $11 \mathrm{~m}$, significant hanging wall failure occurred to within $2 \mathrm{~m}$ of a permanent infrastructure, as shown in Figure 5, resulting in the sterilisation of approximately $25 \%$ of the resource since pillars were required to be left. 

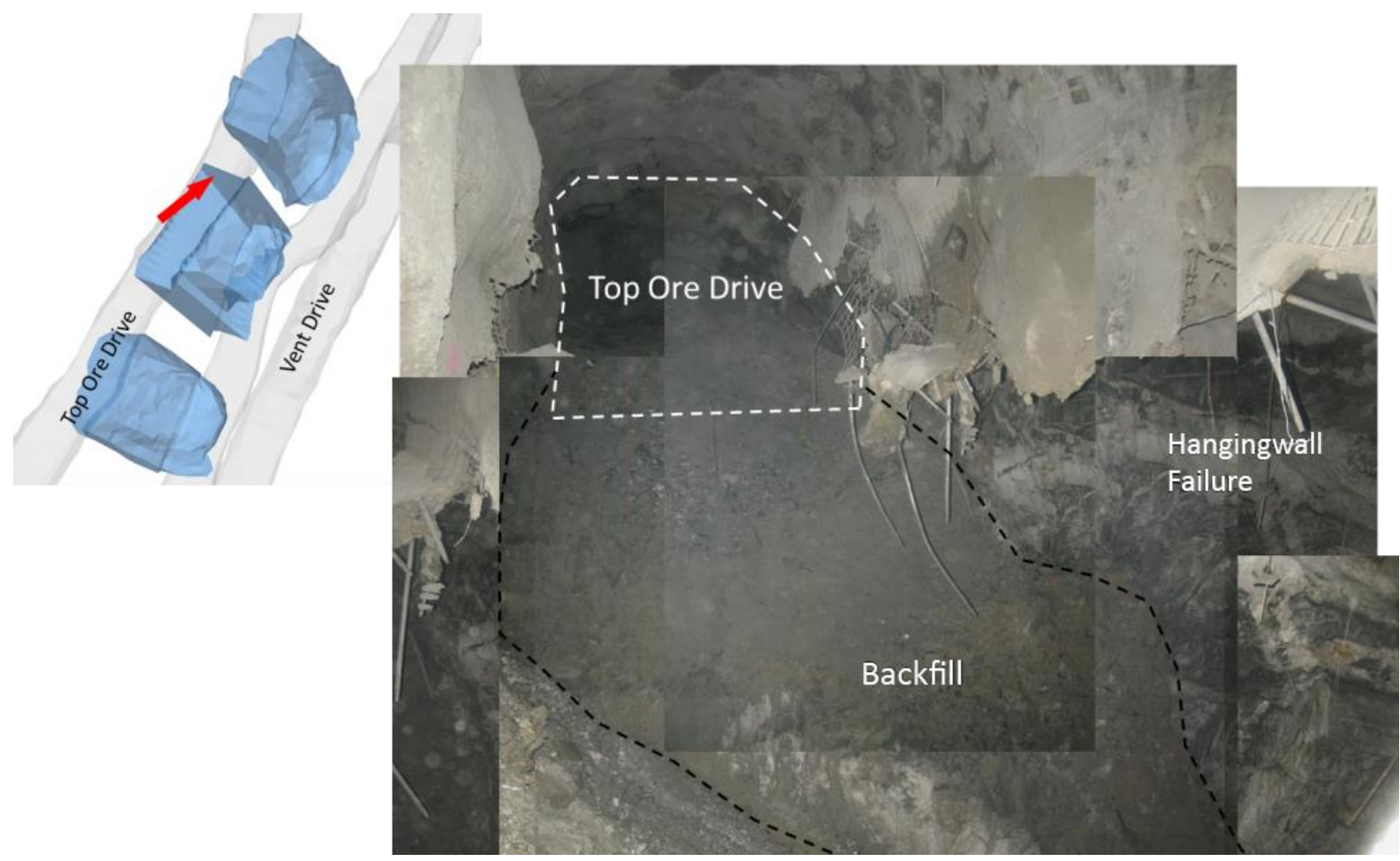

Figure 5 Observed hanging wall failure - Ballarat Gold Project

The DFN geometry of the hanging wall rock mass was reconstructed using measures of GSI from scanline mapping and borehole data. This same dataset was also used for the empirical design approach. A comparison of the observed and simulated DFN statistics is provided in Table 3.

Table 3 Ballarat Gold Project: DFN statistical characteristics

\begin{tabular}{|c|c|c|c|c|c|c|c|}
\hline & \multirow{2}{*}{\multicolumn{2}{|c|}{$\begin{array}{cc} & \text { Rock mass } \\
& \begin{array}{c}\text { Average block } \\
\text { volume } \\
\end{array} \\
\text { GSI } & \left(\mathrm{m}^{3}\right)\end{array}$}} & \multicolumn{2}{|c|}{ Bedding partings } & \multicolumn{3}{|c|}{ Orthogonal jointing } \\
\hline & & & $\begin{array}{l}\text { Average } \\
\text { spacing } \\
\text { (m) }\end{array}$ & $\begin{array}{c}\text { Spacing } \\
\text { range } \\
\text { (m) }\end{array}$ & $\begin{array}{c}\text { Average } \\
\text { spacing } \\
\text { (m) }\end{array}$ & $\begin{array}{l}\text { Spacing } \\
\text { range } \\
\text { (m) }\end{array}$ & $\begin{array}{l}\text { Persistence } \\
\text { (m) }\end{array}$ \\
\hline Observed & 35 & 0.01 & 0.1 & $0.05-0.2$ & 0.03 & $0.2-0.5$ & 0.3 \\
\hline Simulated & 39 & 0.0097 & 0.08 & $0.03-0.1$ & 0.026 & $0.01-0.61$ & 0.3 \\
\hline
\end{tabular}

The simulated rock mass fabric shown on a cross-section through the location of the failed stope is provided in Figure 6, along with a photograph of the rock mass exposure in this area. 


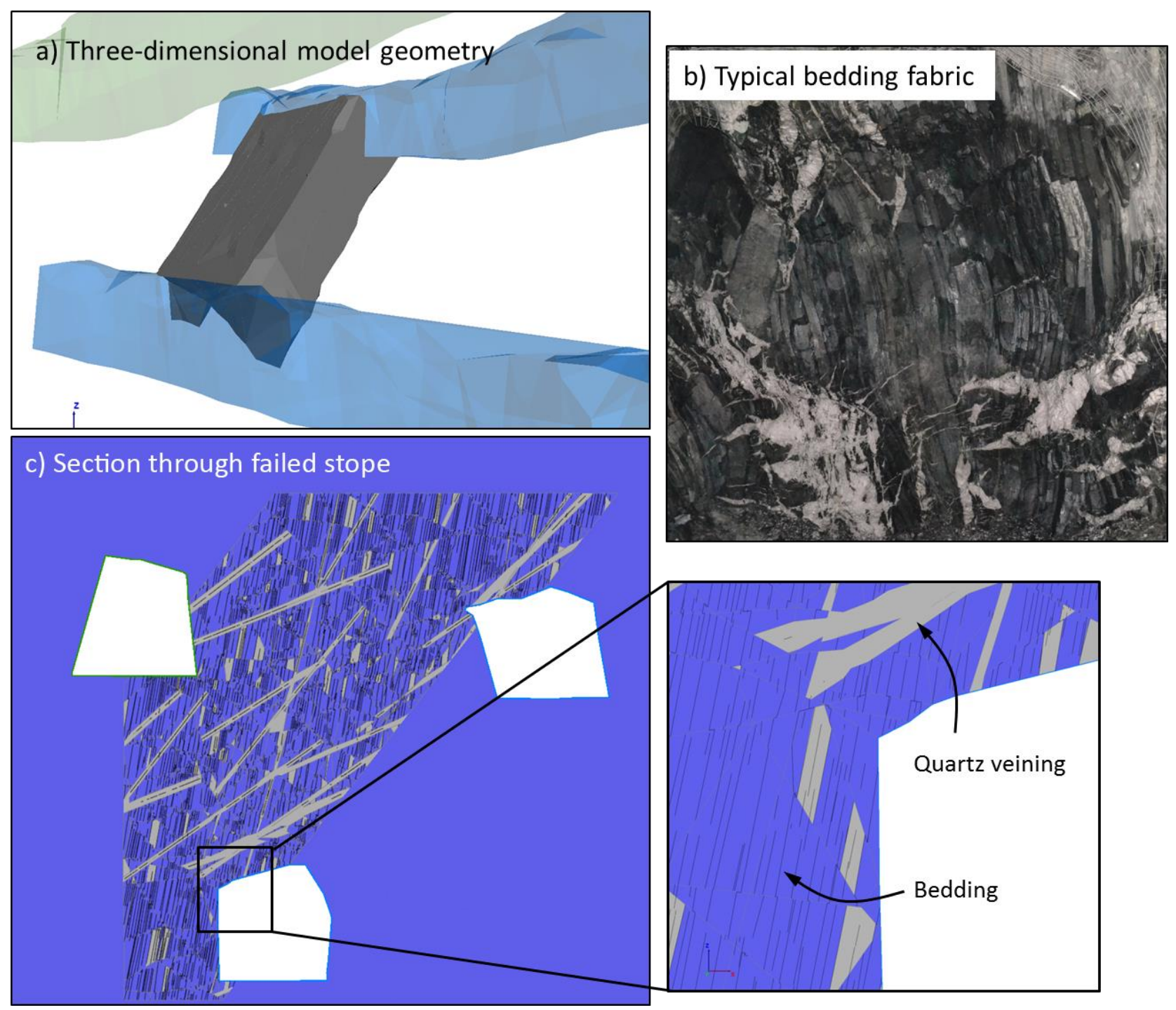

Figure 6 Simulated rock mass fabric shown on a cross-section through the location of the failed stope is provided. Grey regions represent quartz veins that represent $5-10 \%$ of the hanging wall rock mass in this area

The conditions in the hanging wall rock mass immediately prior to stoping (e.g. immediately after development) are presented in Figure 7. A detailed description of the stope geometry and the extraction sequence are described in Sainsbury et al. 2014. 

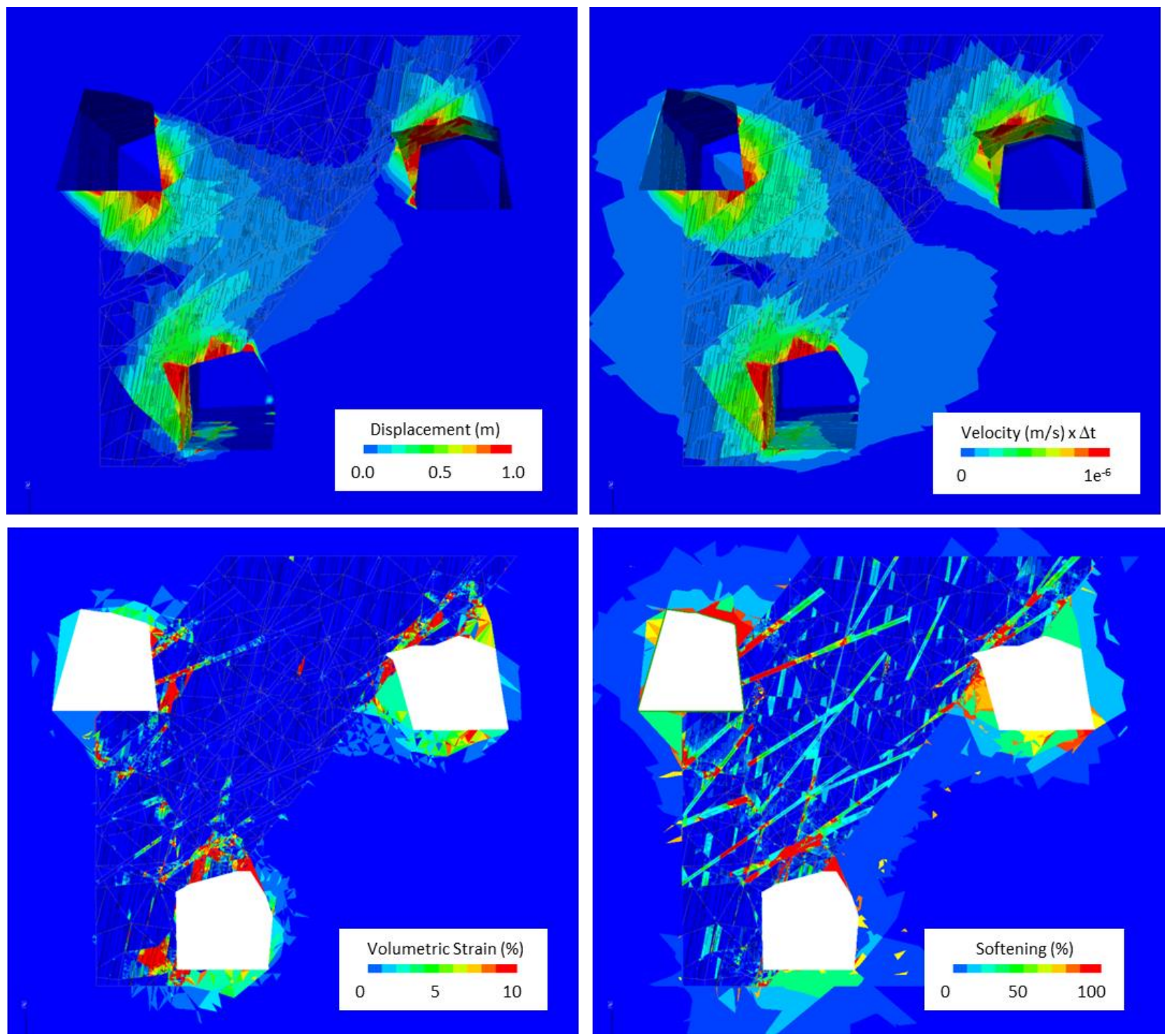

Figure 7 Simulated rock mass conditions on a section through the stope after the completion of ore drive development

Simulated horizontal convergence in the hanging wall access drive compared well to the observed displacements (up to $375 \mathrm{~mm}$ measured at mid-height) immediately prior to stoping. In addition, geotechnical inspections of the area observed ongoing instability in the toe of the hanging wall drive along with the shoulders of the ore drives (as presented in the red areas of the velocity plots provided in Figure 7. The simulated volumetric strain and softening profiles are also consistent with the damage observed immediately prior to stoping. Here, the brittle nature of the quartz veins is clearly observed with the majority of the quartz losing $50-100 \%$ of its strength during development.

The numerical results after simulating the extraction of the $11 \mathrm{~m}$ stope are presented in Figure 8 . In each of the plots, the red area highlights that rock mass in the numerical model is unstable. The black line represents the three-dimensional CMS pick-up after full extraction and stabilisation of the hanging wall. 

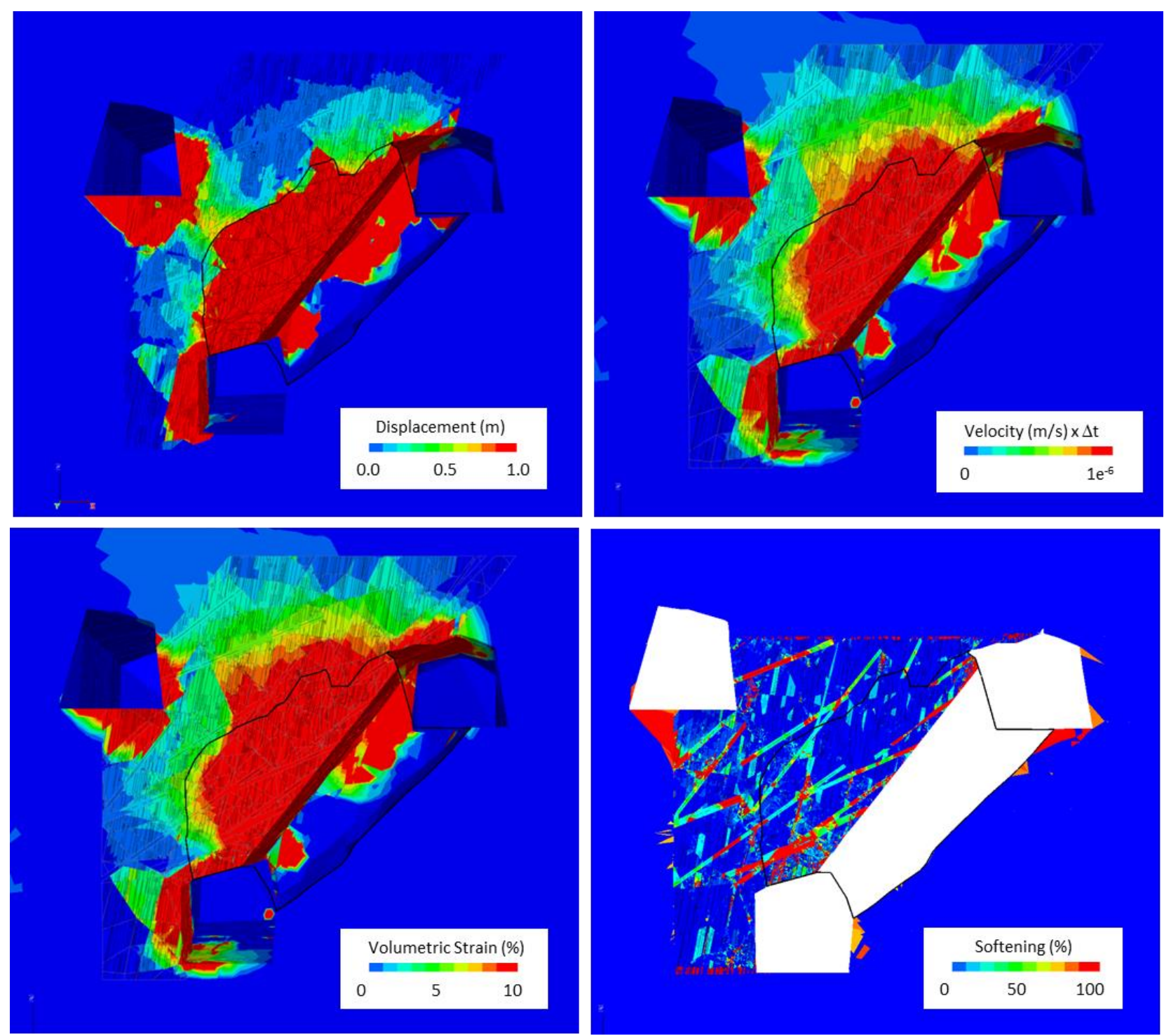

Figure 8 Simulated rock mass conditions on a section through the stope after extraction of the $11 \mathrm{~m}$ stope

The hanging wall instability is illustrated in the numerical simulations through the assessment of displacement, velocity, volumetric strain and softening. The dilution volume in the model has been calculated by summing all the zone volumes that have a displacement greater than $1 \mathrm{~m}$, a velocity greater than $1 \mathrm{e}^{-6} \mathrm{~m} / \mathrm{s}$ and a volumetric strain greater than $3 \%$. Based on this volume, an ELOS of $3.75 \mathrm{~m}$ has been simulated. The simulated dilution volume in the model is presented in Figure 9 along with the CMS pick-up after full extraction. Back-analysis of the observed conditions allows a calculation of an ELOS of $3.5 \mathrm{~m}$. 


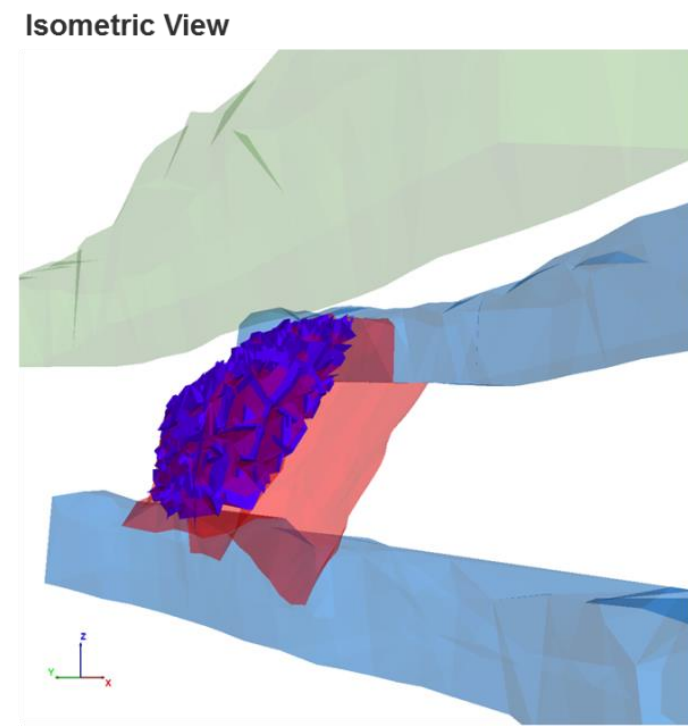

\section{Section View}

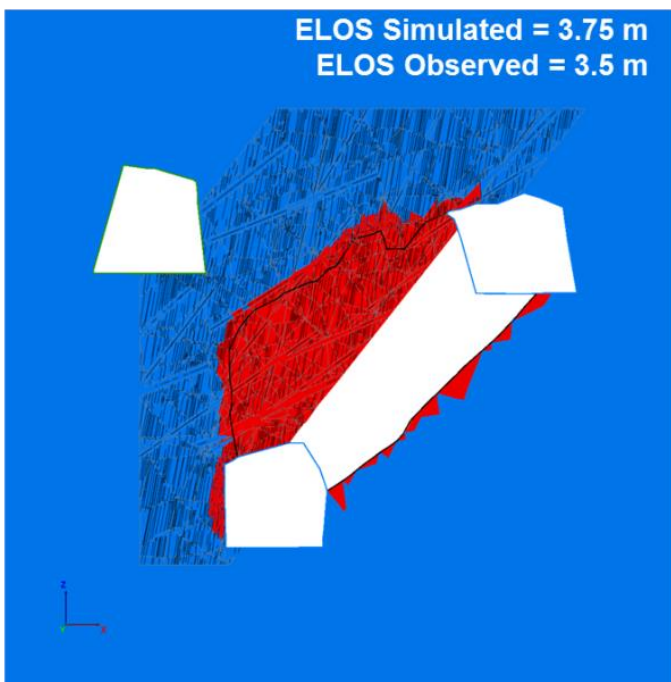

Figure 9 ELOS simulated in numerical model compared to CMS pick-up after extraction of the $11 \mathrm{~m}$ stope

Using the same geotechnical dataset for both design approaches, which was collected prior to development of the stope, the analysis of the Ballarat Gold Project stope case study has shown that the use of numerical methods was able to accurately capture the hanging wall failure in this instance that was not predicted by empirical design methods.

\subsection{Crown stability - numerical case study application}

The stability of two alternate crown geometries (HR 7.3 and 12.8) of a stoping operation has been assessed through empirical and numerical modelling techniques. Empirical predictions have been made using the parameters presented in Figure 10. A critical joint orientation of $20^{\circ} / 23^{\circ}$ has been selected based on an assessment of the rock mass DFN presented in Figure 11.

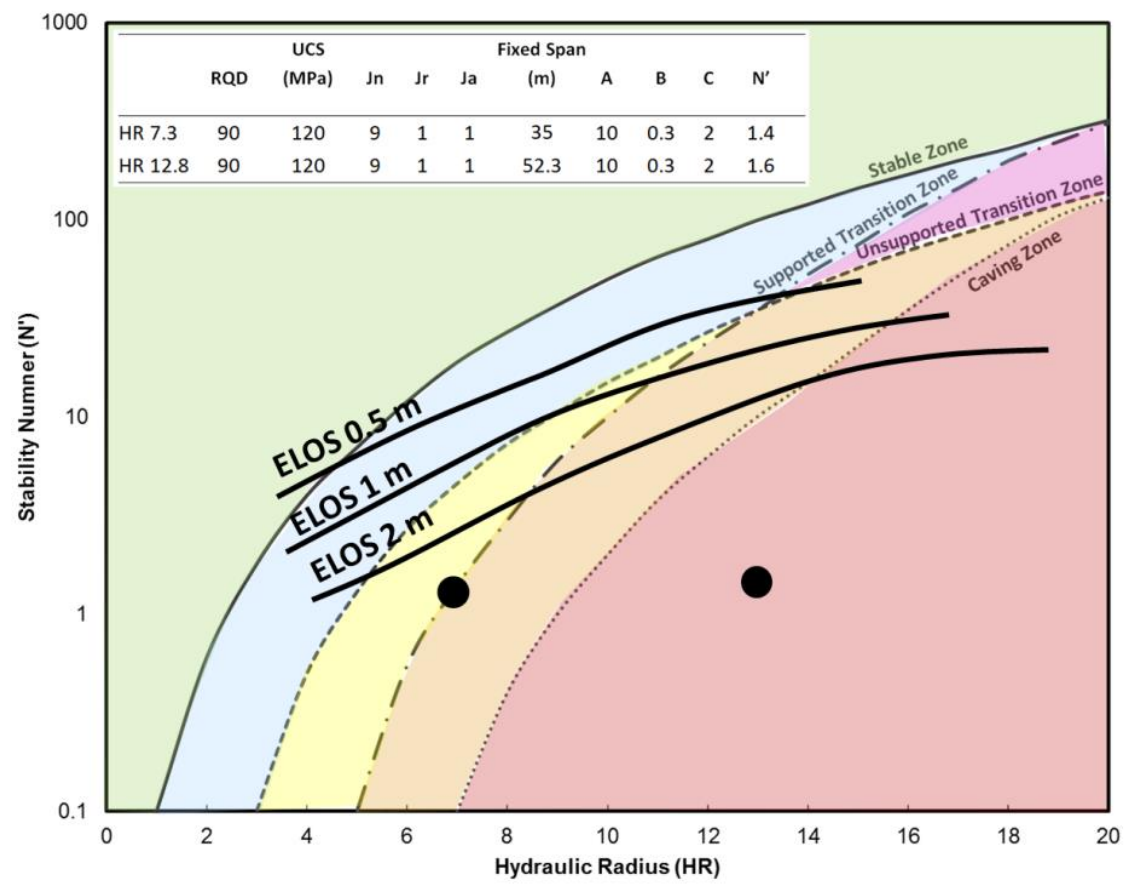

Figure 10 Empirical stope stability and ELOS assessment (modified after Mathews et al. 1981;

Potvin 1988; Clark \& Pakalanis 1997) 
The empirical design methods suggest that the stope geometry with a HR of 7.3 is expected to be marginally stable if support is installed. The larger stope geometry (HR 12.8) can be expected to experience crown failure. An ELOS of greater than $2 \mathrm{~m}$ is predicted in both cases.

A numerical analysis of each of the stope geometries is able to provide a quantitative assessment of the expected dilution. A synthetic DFN has been constructed with characteristics described in Figure 11. The DFN has been developed based on estimates of GSI (79) and a description of the joint conditions (fair) that relates to a block size in excess of $150 \mathrm{~cm}^{3}$ (Cai et al. 2007). An assessment of the joint orientations, spacing and persistence allows the development and calibration of a DFN that is presented in Figure 11.

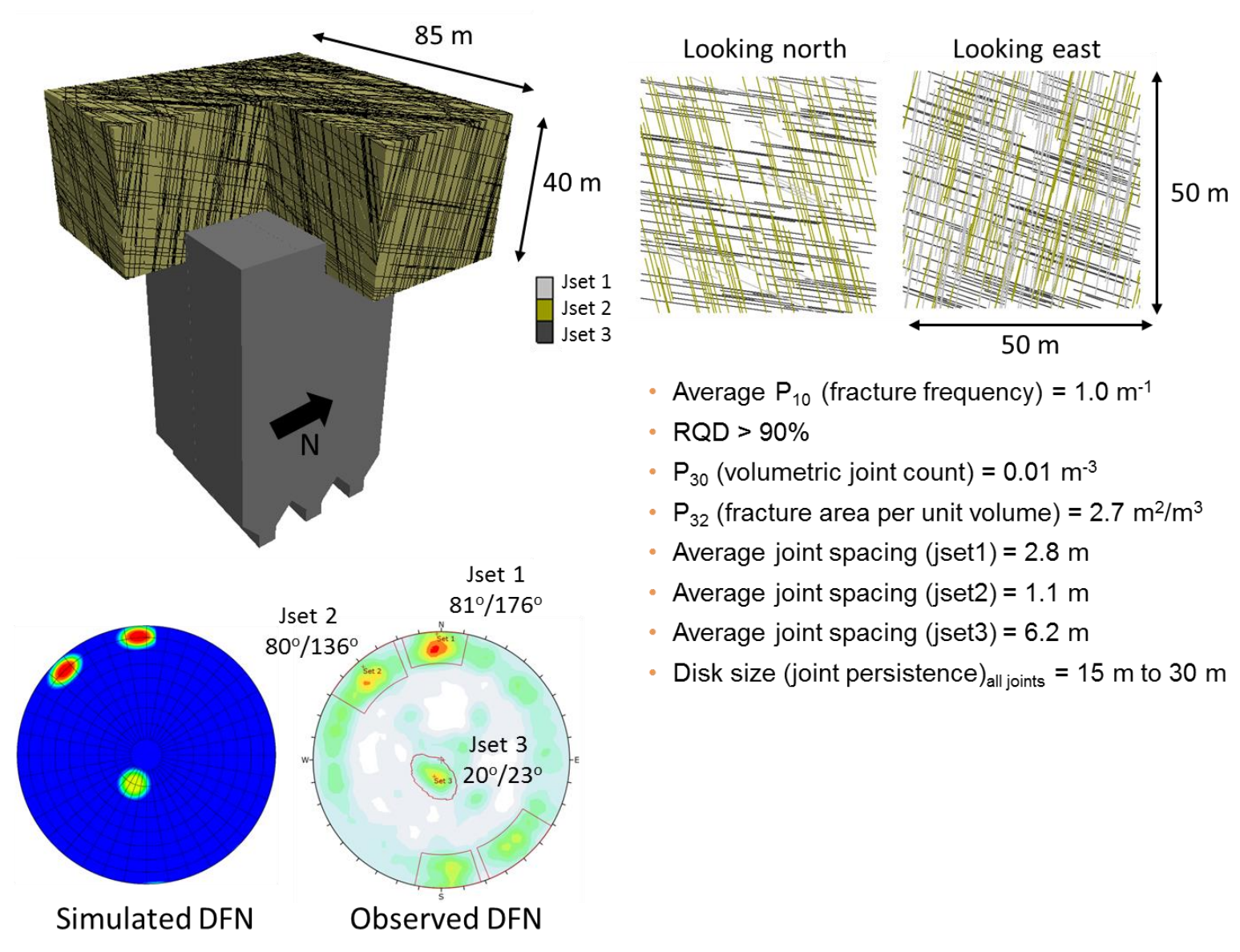

Figure 11 Characteristic DFN properties and resulting joint fabric simulated in the back of the stope(s)

The numerical response of the DFN has been characterised through the simulated testing of representative elemental volumes (REV) of synthetic rock mass at three confinement levels: 0,5 and $10 \mathrm{MPa}$, the results of which are presented in Figure 12. 


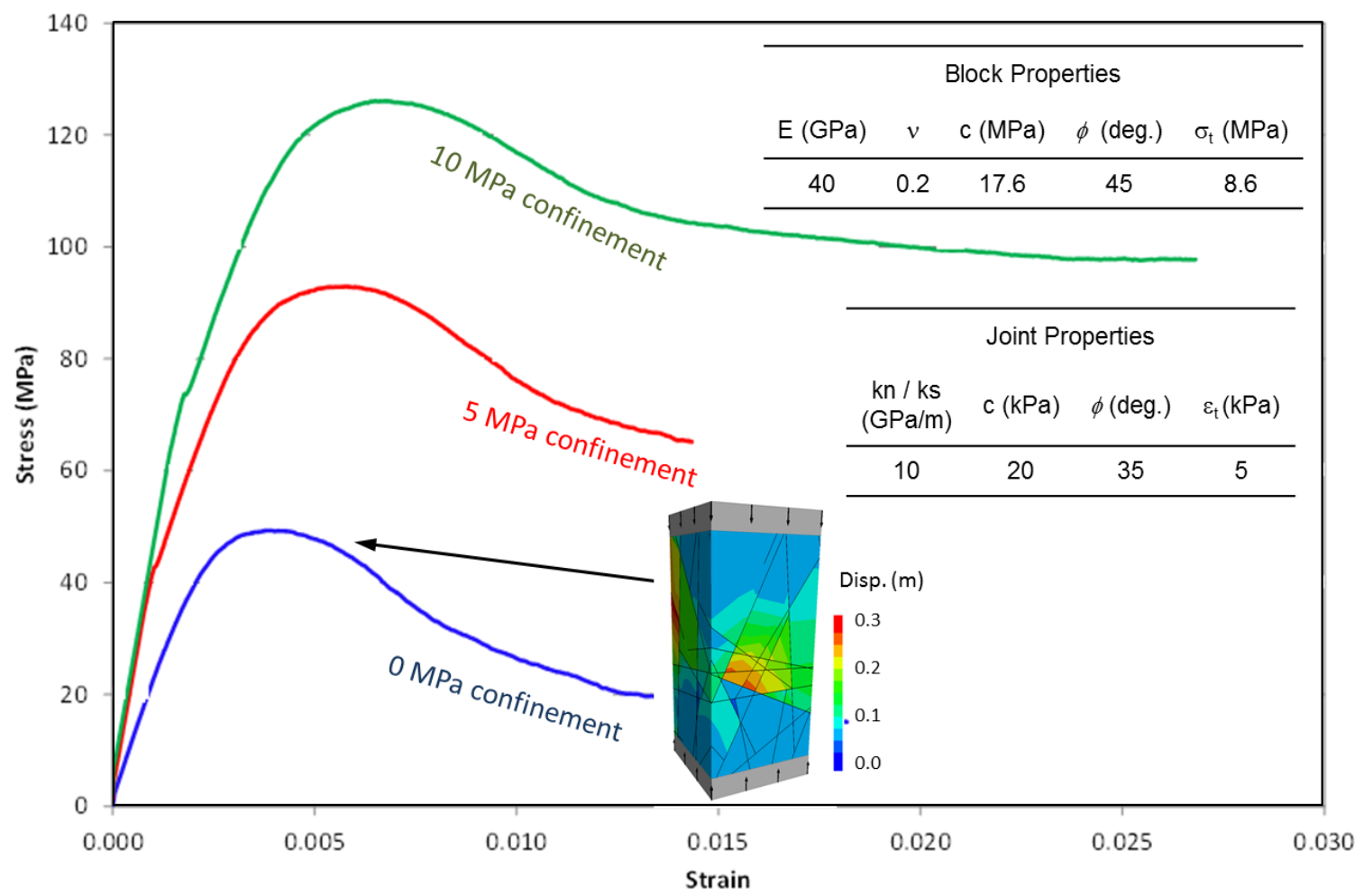

Figure 12 Characterisation of rock mass response at different confinement levels. The numerical block and joint input parameters used to generate this response are also provided

The synthetic responses have been verified through a comparison to the Hoek-Brown strength estimates with input properties of unconfined compressive strength (UCS) equal to $143 \mathrm{MPa}$ and $\mathrm{m}_{i}$ of 16.8 . Three random samples have been populated with the DFN to confirm the results. The simulated laboratory responses are presented in Figure 13.

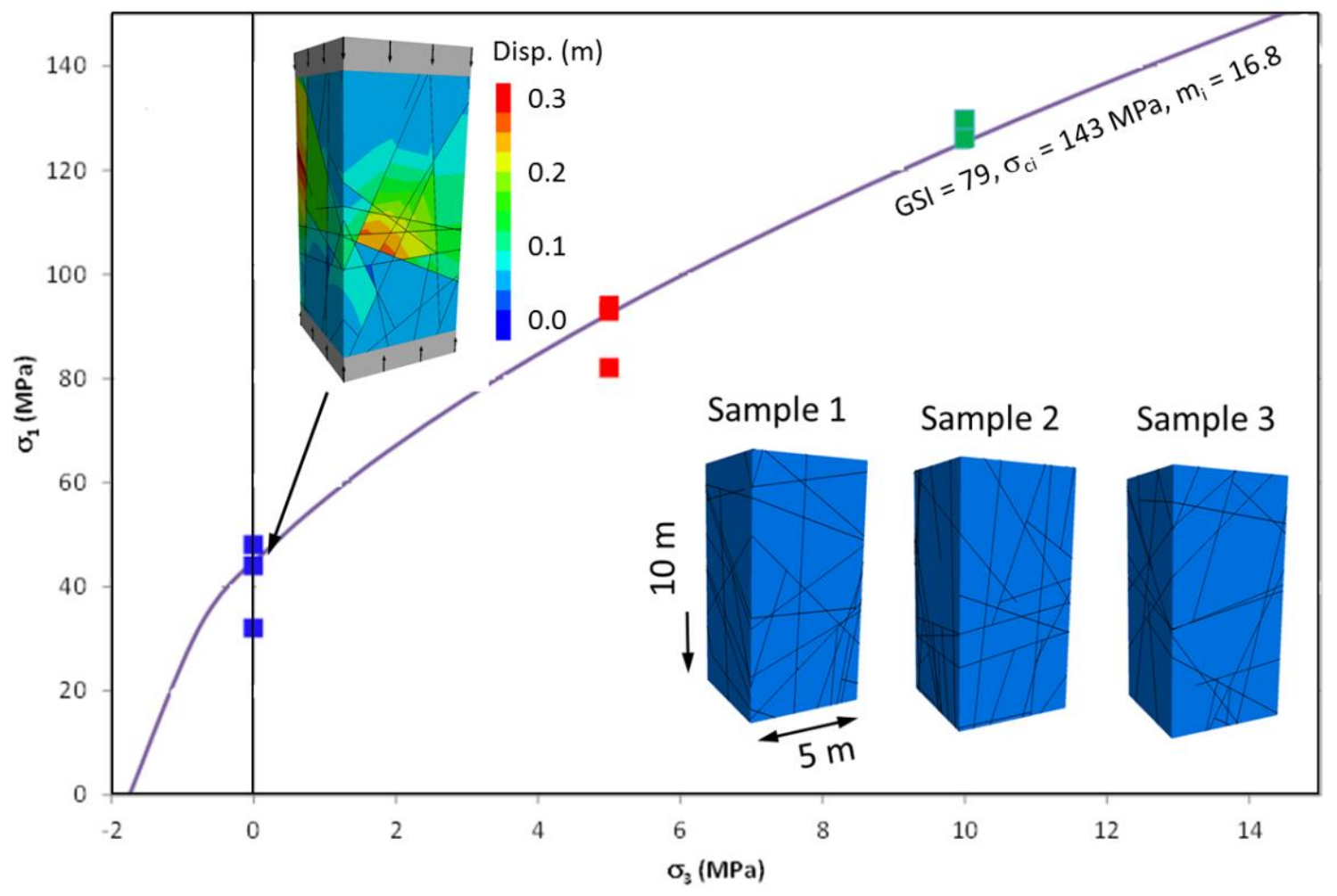

Figure 13 Verification of synthetic DFN through comparison to Hoek-Brown response at REV volume 
The stability of the two crown geometries has been assessed in a three-dimensional explicit model using the DFN developed and validated in Figures 12 and 13. The crown stability results are presented in Figure 14.

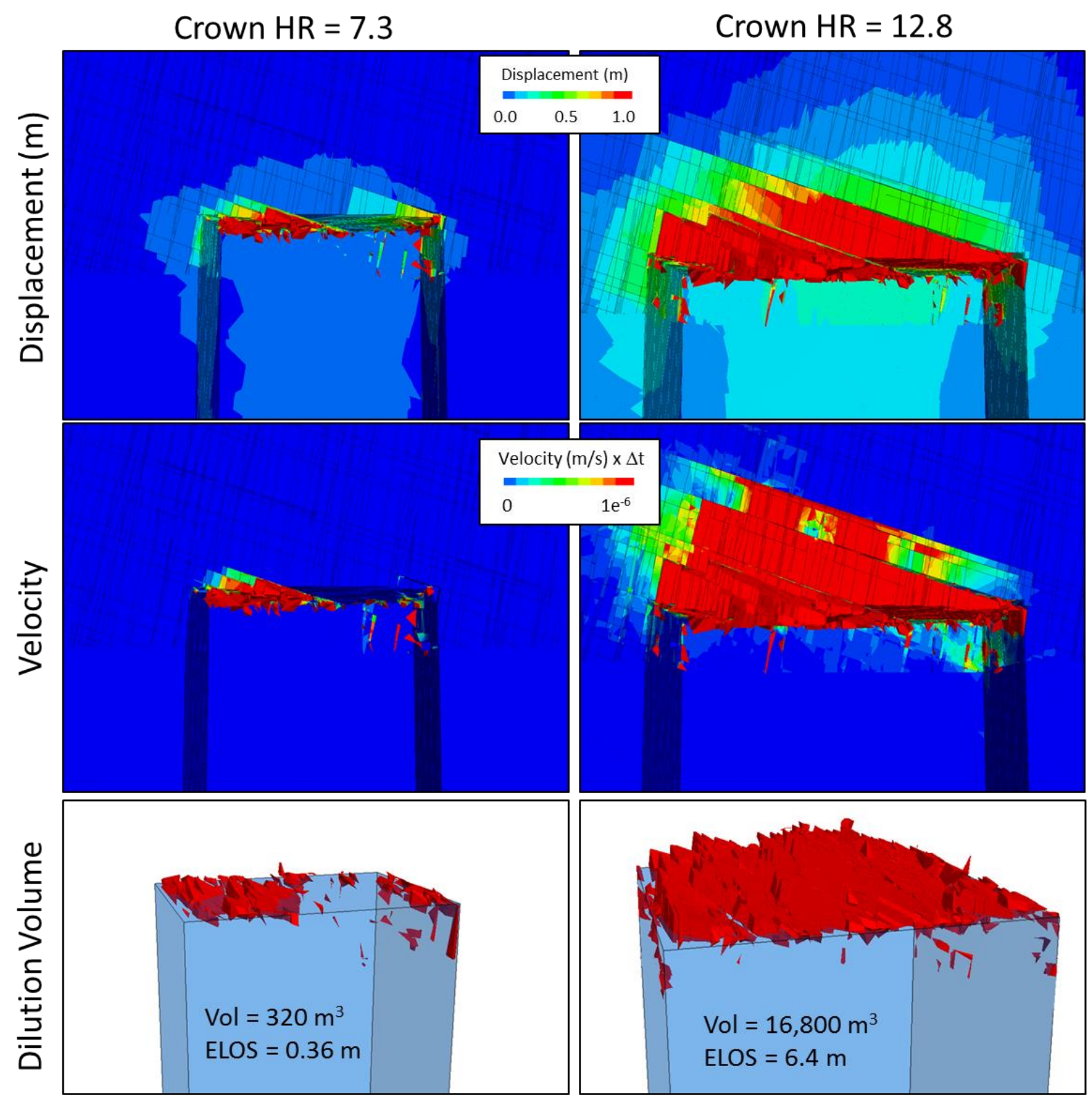

Figure 14 Simulated stability of the two stope crown geometries considered

A significant increase in dilution with the increased HR is observed. An ELOS of 0.36 and $6.4 \mathrm{~m}$ is simulated with the increase in HR from 7.3 to 12.8 respectively. The simulations are able to provide a more quantitative and robust prediction of the crown instability than the empirical approaches that provide ELOS predictions of greater than $2 \mathrm{~m}$ for both geometries.

\section{Conclusion}

Three-dimensional discrete analysis simulations are not expected to be used routinely in conceptual studies, but are suggested to be used in early to late stages of development of a stoping operation when significant rock mass data sets are available to provide design reliabilities in excess of $80 \%$. They provide a rational design tool to enable mine operators to make economic decisions that will also ensure a safe working environment (Vongpaisal et al. 2009). 
A numerical modelling methodology has been developed and has proven successful in simulating stope performance at a narrow vein mining operation. The technique is currently being used as an alternate design tool at a number of local narrow vein stoping operations. The development of robust numerical modelling methodologies allows the integration of technology across the mine value chain that will facilitate a more efficient and sustainable operation that can better manage risk. This is achieved through the development of a mining design that, from inception, considers actual stope dimensions, stope wall orientations, extraction sequence, in situ stresses, discrete joint fabric and rock mechanical properties through a process of integrated design, instrumentation and reconciliation.

The numerical modelling approach is not considered appropriate in all situations; however, as demonstrated with the Ballarat Gold Project case study, through a variation in the design technique, the design reliability is increased from less than $50 \%$ to approximately $80 \%$ (Cepuritis \& Villaescusa 2012), using the same geotechnical dataset.

\section{Acknowledgment}

The authors thank the management team at the Ballarat Gold Project for the permission to present this work.

\section{References}

Andrieux, PP, Brummer, RK, Li, H \& O'Connor, CP 2007, 'Elastic versus inelastic numerical modelling of deep and highly stresses mining fronts', in Y Potvin (ed.), Proceedings of the Fourth International Seminar on Deep and High Stress Mining (Deep Mining '07), Australian Centre for Geomechanics, Perth, pp. 51-64.

Berry, M \& McCarthy, P 2006, 'Practical consequences of geological uncertainty', Proceedings of the Sixth International Mining Geology Conference, The Australasian Institute of Mining and Metallurgy, Melbourne, pp. 253-258.

Bewick, R \& Kaiser, PK 2009, 'Numerical assessment of factor B in Mathews' method for open stope design', in M Diederichs \& G Grasselli (eds), Proceedings of the Third Canada-US Rock Mechanics Symposium and the 20th Canadian Rock Mechanics Symposium (RockEng09), pp. 89-90.

Cai, M, Kaiser, PK, Tasaka, Y \& Minami, M 2007, 'Determination of residual strength parameters of jointed rock masses using the GSI system', International Journal of Rock Mechanics and Mining Sciences, vol. 44, pp. 247-265.

Capes, G 2009, 'Open stope hangingwall design based on general and detailed data collection in rock masses with unfavourable hangingwall conditions' PhD thesis, University of Saskatchewan.

Cepuritis, P \& Villaescusa, E 2012, 'A reliability-based approach to open stope span design in underground mining', Proceedings of the 6th International Conference and Exhibition on Mass Mining (MassMin 2012), Canadian Institute of Mining, Metallurgy and Petroleum, Westmount, QC, CD-Rom only.

Clark, LM \& Pakalnis, RC 1997, 'An empirical design approach for estimating unplanned dilution from open stope hangingwalls and footwalls', Proceedings of the CIM 99th Annual General Meeting, Canadian Institute of Mining, Metallurgy and Petroleum, Westmount, QC.

Martin, CD 1997, 'Seventeenth Canadian Geotechnical Colloquium: The effect of cohesion loss and stress path on brittle rock strength', Canadian Geotechnical Journal, vol. 34, no. 5, pp. 698-725.

Martin, CD, Tannant, DD, Yazici, S \& Kaiser, PK 1999, 'Stress path and instability around mine openings', Proceedings of the 9th ISRM Congress, International Society for Rock Mechanics, pp. 25-28.

Matthews, KE, Hoek, E, Wyllie, DC \& Stewart, S 1981, Prediction of stable excavation spans for mining at depths below 1,000 metres in hard rock / Golder Associates, CANMET Library \& Documentation Services Division, Vancouver.

Mawdesley, C, Trueman, R \& Whiten, WJ 2001, 'Extending the Mathews stability graph for open stope design', Mining Technology, vol. 110, no. 1, pp. 27-39.

Oddie, ME \& Pascoe, MJ 2005, 'Stope performance at Olympic Dam Mine', Proceedings of the Ninth Underground Operators' Conference, The Australasian Institute of Mining and Metallurgy, Melbourne, pp. 265-272.

Parrott, T \& Keall, P 2010, Stope performance in challenging ground conditions: observed versus predicted - a case study, Proceedings of the Second Australasian Ground Control in Mining Conference, The Australasian Institute of Mining and Metallurgy, Melbourne, $9 \mathrm{p}$.

Potvin, Y 1988, 'Empirical open stope design in Canada' PhD thesis, University of British Columbia.

Sainsbury, B, Sainsbury, D, Western, J, Petrie, P \& Mutton, V 2014, 'Pillar recovery adjacent to stabilised rockfill at the Ballarat Gold Project', Proceedings of the Third Australasian Ground Control in Mining Conference (AusRock 2014), The Australasian Institute of Mining and Metallurgy, Melbourne, Paper no. 29.

Sharp, J 2011, 'Applicability of the Mathews stability method to open stope stability assessment at Olympic Dam Mine' Masters thesis, University of Canterbury. 
Sprott, D, Toppi, M, Yi, X \& Bawden, WF 1999, 'The incorporation of stress induced damage factor into the Mathew's stability graph', Proceedings of the CIM 101st Annual General Meeting, Canadian Institute of Mining, Metallurgy and Petroleum, Westmount, Quebec.

Stewart, PC \& Trueman, R 2008, 'Strategies for minimising and predicting dilution in narrow-vein mines - NVD Method', Proceedings of the Narrow Vein Mining Conference, The Australasian Institute of Mining and Metallurgy, Melbourne, pp. 153-164.

Suorineni, F 2010, 'The stability graph after three decades in use: experiences and the way forward', International Journal of Mining, Reclamation and Environment, vol. 24, no. 4, pp. 307-339.

Suorineni, FT, Tannant, DD \& Kaiser, PK 1999, 'Determination of fault-related sloughage in open stopes', International Journal of Rock Mechanics and Mining Sciences, vol. 36, no. 7, pp. 891-906.

Vongpaisal, S, Li, G, Pakalnis, R \& Brady, T 2009, 'New 3D engineering curves for predicting stope stability and mining dilution in longitudinal blasthole mining operations', International Journal of Mining, Reclamation and Environment, vol. 23, no. 2, pp. 92-102. 